\author{
15-17 February, 2019 in Rome-Italy
}

\title{
Stretching Too Much? The Impact of Cross-Gender Brand Extensions on Consumer-Brand Relationships
}

\author{
Aravind Reghunathan and Joshy Joseph \\ Indian Institute of Management Kozhikode, India
}

\begin{abstract}
Consumers generally perceive gender identities on many brands in the marketplace. It can be seen that they tend to place brands such as Hugo Boss, Marlboro, Hot wheels in masculine category and L'Oréal, Triumph, Barbie in feminine category. At the same time, a recent phenomenon shows certain brands, typically associated with any one particular gender, extending into the opposite gender category using the same brand name. The brand 'Pond's', which has traditionally been perceived as a feminine brand, extending to the men's segment with 'Pond's for men' is a typical example. Such cross-gender brand extensions clearly represents a departure from traditional branding practices of companies using two different brands to target the two different gender segments. This paper argues that extending a gendered brand into the opposite gender category affects the strength of consumer-brand relationships. Significant gender differences in this effect are observed, which can have implications for marketing to men vis-à-vis marketing to women. Specifically, men have higher relationship strength with the brands that align with their gender identities and as a result, the negative impact when a masculine brand extends to the feminine category is higher, as compared to the negative impact when a feminine brand extends to the masculine category.
\end{abstract}

Keywords: Brand personality, Brand gender, Consumer-brand relationships, Cross-gender brand extensions 